\title{
Fine particulate matter and polycystic ovarian morphology
}

\author{
Victoria Fruh' ${ }^{1 *}$, Jay Jojo Cheng ${ }^{2}$, Ann Aschengrau ${ }^{3}$, Shruthi Mahalingaiah ${ }^{1,4 \dagger}$ and Kevin J. Lane ${ }^{5 \dagger}$
}

\begin{abstract}
Background: Polycystic ovary morphology (PCOM) is an ultrasonographic finding that can be present in women with ovulatory disorder and oligomenorrhea due to hypothalamic, pituitary, and ovarian dysfunction. While air pollution has emerged as a possible disrupter of hormone homeostasis, limited research has been conducted on the association between air pollution and PCOM.

Methods: We conducted a longitudinal cohort study using electronic medical records data of 5,492 women with normal ovaries at the first ultrasound that underwent a repeated pelvic ultrasound examination during the study period (2004-2016) at Boston Medical Center. Machine learning text algorithms classified PCOM by ultrasound. We used geocoded home address to determine the ambient annual average $\mathrm{PM}_{2.5}$ exposures and categorized into tertiles of exposure. We used Cox Proportional Hazards models on complete data $(n=3,994)$, adjusting for covariates, and additionally stratified by race/ethnicity and body mass index (BMI).

Results: Cumulative exposure to $\mathrm{PM}_{2.5}$ during the study ranged from 4.9 to $17.5 \mu \mathrm{g} / \mathrm{m}^{3}$ (mean $=10.0 \mu \mathrm{g} / \mathrm{m}^{3}$ ). On average, women were 31 years old and 58\% were Black/African American. Hazard ratios and 95\% confidence intervals (Cl) comparing the second and third $\mathrm{PM}_{2.5}$ exposure tertile vs. the reference tertile were $1.12(0.88,1.43)$ and $0.89(0.62$, 1.28), respectively. No appreciable differences were observed across race/ethnicity. Among women with $\mathrm{BMI} \geq 30 \mathrm{~kg} /$ $\mathrm{m}^{2}$, we observed weak inverse associations with PCOM for the second (HR: $0.93,95 \% \mathrm{Cl}: 0.66,1.33$ ) and third tertiles (HR: 0.89, 95\% Cl: 0.50, 1.57).

Conclusions: In this study of reproductive-aged women, we observed little association between $\mathrm{PM}_{2.5}$ concentrations and PCOM incidence. No dose response relationships were observed nor were estimates appreciably different across race/ethnicity within this clinically sourced cohort.
\end{abstract}

Keywords: Polycystic ovary morphology (PCOM), Air pollution, Fine particulate matter, Electronic medical records

\section{Background}

Polycystic ovary morphology (PCOM) is an ultrasonographic finding that can be present in women with ovulatory disorder and oligomenorrhea due to hypothalamic, pituitary, and ovarian dysfunction [1-3]. PCOM may be seen in multiple endocrine states where follicular

\footnotetext{
*Correspondence: vfruh@hsph.harvard.edu

†Shruthi Mahalingaiah and Kevin J. Lane are co-senior authors.

${ }^{1}$ Department of Environmental Health, Harvard T.H. Chan School of Public Health, Boston, MA, USA

Full list of author information is available at the end of the article
}

development is altered, resulting in arrested antral follicles [4]. PCOM has been observed in about 30-50\% of patients with functional hypothalamic amenorrhea [5-7] and is more common in women with Cushing's disease [8]. Women with polycystic ovary syndrome (PCOS), a disease notable for oligomenorrhea and androgen excess, and PCOM have demonstrated higher risks of insulin resistance, dyslipidemia and cardiovascular diseases compared to women with only PCOS [9]. The clinical significance of PCOM alone is undefined as previous literature on direct health impacts of PCOM remains sparse. However, some studies have observed original author(s) and the source, provide a link to the Creative Commons licence, and indicate if changes were made. The images or other third party material in this article are included in the article's Creative Commons licence, unless indicated otherwise in a credit line to the material. If material is not included in the article's Creative Commons licence and your intended use is not permitted by statutory regulation or exceeds the permitted use, you will need to obtain permission directly from the copyright holder. To view a copy of this licence, visit http://creativecommons.org/licenses/by/4.0/. The Creative Commons Public Domain Dedication waiver (http://creativeco mmons.org/publicdomain/zero/1.0/) applies to the data made available in this article, unless otherwise stated in a credit line to the data. 
associations between PCOM and elevated anti-Müllerian hormone (AMH) among healthy girls with regular menses [10], as well as a higher severity of primary dysmenorrhea [11].

Air pollution has emerged as a possible disrupter of hormone homeostasis interfering with the female reproductive system [12, 13]. Epidemiologic studies have begun to evaluate specific reproductive health outcomes in relation to environmental air pollution including infertility [14-17], hormone function [18, 19], and menstrual cycle status [20-22]. Likewise, animal studies have investigated associations between ovarian function and air pollution, finding significant decreases in the area occupied by primordial follicles for mice exposed to pollutants from diesel exhaust [23] and changes in AMH levels for mice exposed to fine particulate matter $\left(\mathrm{PM}_{2.5}\right)$ [24]. However, there is a dearth of research on the association between $\mathrm{PM}_{2.5}$ and PCOM. One study to date has evaluated $\mathrm{PM}_{2.5}$ and PCOS, rather than PCOM [25], and observed an increased risk of PCOS with higher levels of $\mathrm{PM}_{2.5}$ [25]. However, this study assessed air pollution one year before diagnosis without investigating potentially longer windows of exposure and diagnosed PCOS via ICD-9-CM codes [25].

In the current study, we investigated the association between $\mathrm{PM}_{2.5}$ and PCOM in a population of reproductive-age women receiving clinical care. Women in our study had a minimum of four years of exposure data prior to diagnosis. We hypothesized that higher levels of $\mathrm{PM}_{2.5}$ would be associated with increased incidence of PCOM.

\section{Methods}

\section{Study population}

This study was conducted at Boston University Medical Campus (BUMC), an academic research medical center in Boston, Massachusetts which includes Boston University School of Medicine (BUSM) and Boston Medical Center (BMC). BMC is the largest safety-net hospital in New England. Greater than 50\% of BMC patients come from underserved populations that depend on government coverage for health expenses through programs like Medicare, Medicaid, and the Health Safety Net [26]. In $2009,34.4 \%$ of the population treated at BMC was White, $31.5 \%$ was Black and $17.6 \%$ was Hispanic/Latino [27].

The BUMC and BUSM Institutional Review Board approved the protocol. Using electronic medical records (EMR) data, we identified patients who attended outpatient clinic visits as described by Cheng et al. [28]. Briefly, all pelvic ultrasounds from October 1, 2003 through December 12, 2016 were retrieved from the BMC Clinical Data Warehouse (CDW) for women of reproductive age (i.e., between 18 and 45 years old), excluding women with a previous diagnosis of endocrinopathy noted by the following ICD-9 codes and descriptions: 182.0 Malignant neoplasm of corpus uteri, except isthmus; 240.0 Simple Goiter; 240.9 Goiter unspecified; 241.0 Nontoxic uninodular goiter; 241.1 Nontoxic multinodular goiter; 242 Thyrotoxicosis with or without goiter; 243 Congenital hypothyroidism, 244 Acquired hypothyroidism; 245 Thyroiditis; 246 Other disorders of thyroid; 255.0 Cushings Syndrome; 255.1 Hyperaldosteronism; 255.2 Adrenogenital disorders; 255.3 Other corticoadrenal overactivity; 255.4 Corticoadrenal insufficiency; 255.5 Other adrenal hypofunction; 255.6 Medulloadrenal hyperfunction; 255.8 Other specified disorders of adrenal glands; 255.9 Unspecified disorders of adrenal glands; 256.8 Other ovarian dysfunction, in order to determine incidence of PCOM among healthy participants without this previous diagnosis. This process yielded 25,535 unique patient IDs [28]. The time period for data query corresponds to the entire period when ICD-9 coding was in use at BUMC.

\section{Study design: longitudinal cohort approach}

We applied a longitudinal cohort approach using the EMR derived dataset. We identified women undergoing an initial and follow-up transvaginal pelvic ultrasound who received care from 2004-2016 and lived in Massachusetts during this timeframe. Patients were followed through 2016, the last year that air pollution data was available. The first pelvic ultrasound examination over the study period was designated as the initial visit. To establish that women were at risk of PCOM but free of this condition at initial visit, we included only women who had normal ovaries as assessed by the first ultrasound $(n=5,492)$. Follow-up pelvic ultrasound examinations determined the incidence of PCOM.

\section{Exposure assessment: measurement of fine particulate matter $\mathbf{P M}_{2.5}$}

We estimated ambient annual average $\mathrm{PM}_{2.5}$ using the North American $\mathrm{PM}_{2.5}$ model based on the combination of aerosol optical depth (AOD) measurements, the chemical transport model (GEOS-Chem) and geographically weighted regression results, as previously described [29]. Briefly, geophysical $\mathrm{PM}_{2.5}$ estimates were consistent with those of globally distributed monitors on the ground $\left(R^{2}=0.81\right.$; slope $\left.=0.90\right)$. Geographically weighted regression was also used to account for the residual bias of monitors, producing higher cross validated agreement with ground monitors $(\mathrm{R} 2=0.90$ 0.92; slope $=0.90-0.97$ ) [29]. The $\mathrm{PM}_{2.5}$ model yields annual average $\mathrm{PM}_{2.5}$ concentration estimates globally at $1 \times 1 \mathrm{~km}$ resolution, and results are compiled in a freely available database (https://sites.wustl.edu/acag/datasets/ surface-pm2-5/\#V4.NA.03). These AOD measurements are available at high temporal resolution and provide a 
historical repository that can be used to retrospectively model $\mathrm{PM}_{2.5}$ [30-34]. Annual average $\mathrm{PM}_{2.5}$ exposure data starting in the year 2000 were matched to geocoded home addresses from the patient's initial visit using Esri ArcPro version 2.2 and SAS v. 9.4.

\section{Outcome assessment: diagnosis of PCOM}

We used the novel technique of identifying PCOM or polycystic ovaries based on radiologic report data as described previously using the Rule Based Classifier Model based on the Rotterdam criteria [2, 28]. Briefly, an ovary was defined as "PCOM-present" if there were 12 or more $2-9 \mathrm{~mm}$ follicles in each ovary and/or if ovarian volume was greater than $10 \mathrm{~mL}$ without the presence of confounding pathology [2, 28, 35-37]. Confounding pathology included presence of a dominant follicle $(>10 \mathrm{~mm})$, corpus luteum, abnormal cyst, or ovarian asymmetry, in which case further investigation would be warranted. If a) confounding pathology occurred, b) an ovary was not measured, c) the radiologic ultrasound was not mentioned, or d) PCOM was recorded as absent, we categorized the ultrasound as showing no indication of PCOM and compared this population to patients who had a "PCOM-present" diagnosis.

\section{Covariates}

We extracted EMR information from the patient's initial visit on demographic characteristics, including age, race/ ethnicity, marital status, educational attainment, and smoking status. We calculated body mass index (BMI kg/ $\mathrm{m}^{2}$ ) from the height and weight abstracted from this visit. If data on these variables were not available from the initial visit, they were obtained from the visit most proximate to the initial visit within the 2004-2015 timeframe. We restricted our analysis to women with BMIs between $19-54 \mathrm{~kg} / \mathrm{m}^{2}$ [38], as values outside of this range were not verified and were likely related to documentation errors. Calendar year denoted the year of annual average $\mathrm{PM}_{2.5}$ measurement. There were 3,994 women with complete data included in the analysis.

\section{Statistical analysis}

We described the characteristics of the study population using proportions, means and standard deviations. As $\mathrm{PM}_{2.5}$ concentrations were measured yearly, we utilized time-varying Cox proportional hazards models to examine the association between $\mathrm{PM}_{2.5}$ and the incidence of PCOM. Women contributed person-years starting from January 2000 until ultrasound detected PCOM or the last ultrasound visit. The first pelvic ultrasound examination during the study period confirmed that the patient was free of PCOM at the initial visit. Patients were able to contribute 4 to 15 years of person-time for follow-up.
To account for patterns in pollution over time (Figure S1), all models were stratified by age in years and calendar year within the Cox model and were used to estimate hazard ratios (HRs) and 95\% confidence intervals (CIs). We categorized air pollution exposure into tertiles in our main analysis to allow for non-linearity and to account for extreme values. The lowest tertile (tertile 1) was designated as the reference group. We conducted multivariate analyses with covariates hypothesized to be associated with air pollution and with PCOM based on a priori literature and directed acyclic graphs [39] (Figure S2). These models included race/ethnicity, educational attainment, marital status, and smoking status [40-44], with educational attainment and marital status serving as proxies for socioeconomic status/household income. We evaluated patients with complete information on all covariates, $\mathrm{PM}_{2.5}$ based on complete data on geocoded home address, and PCOM $(n=3,994)$. To evaluate if the association between $\mathrm{PM}_{2.5}$ and $\mathrm{PCOM}$ varied by BMI and race/ethnicity, we conducted stratified analyses by these variables. As a sensitivity analysis, we also evaluated 1) women who never moved over the study period $(n=682)$ to determine the impact of possible exposure misclassification due to residential mobility and 2) continuous air pollution models to assess precision without categorical restrictions.

\section{Results}

At initial visit, mean age was 31.1 years among the 3,994 women in the analysis (Table 1 ). The majority of women were Black/African American (57.9\%), never smokers (73.5\%), and not married (75.2\%). About onethird of women graduated high school or received their GED (32.7\%) and about one-quarter attained education beyond high school (27.7\%). Mean BMI at initial visit was $30 \mathrm{~kg} / \mathrm{m}^{3}$. Mean $\mathrm{PM}_{2.5}$ level from 2004-2016 was $10.0 \mu \mathrm{g} /$ $\mathrm{m}^{3}$, over the entire study period (Table 1 ).

HRs comparing the second and third tertiles to the reference (first) tertile were 1.12 (95\% CI: $0.88,1.43)$ and 0.89 (95\% CI: $0.62,1.28$ ), respectively (Table 2, Fig. 1). Thus, we did not observe a dose-response relationships across tertiles. Among women with a $\mathrm{BMI}<30 \mathrm{~kg} / \mathrm{m}^{2}$, HRs comparing the second and third tertiles to the reference tertile were 1.30 (95\% CI: 0.91, 1.88) and 0.89 (95\% CI: $0.53,1.49$ ), respectively (Table 3 ). Among women with $\mathrm{BMI} \geq 30 \mathrm{~kg} / \mathrm{m}^{2}$, we observed weak inverse associations with PCOM for both the second (HR: 0.93, 95\% CI: $0.66,1.33$ ) and third (HR: $0.89,95 \%$ CI: $0.50,1.57)$ tertiles when compared to the reference tertile (Table 3, Fig. 1). When stratified by race/ethnicity, the HRs ( $95 \%$ CI) between $\mathrm{PM}_{2.5}$ and PCOM among Black, Hispanic/ Latino and White women comparing the third tertile to the reference tertile were 0.73 (95\% CI: 0.44, 1.20), 0.93 
Table 1 Characteristics of Patients at Initial Visit* (2004-2015) $(n=3994)$

\begin{tabular}{|c|c|}
\hline & $\%$ or mean $(S D)$ \\
\hline Age (years) & $31.1(7.6)$ \\
\hline \multicolumn{2}{|l|}{ Race/Ethnicity } \\
\hline Black/African American & 57.9 \\
\hline Hispanic/Latino & 5.0 \\
\hline White & 15.1 \\
\hline Other & 4.8 \\
\hline Declined to Answer & 17.2 \\
\hline \multicolumn{2}{|l|}{ Educational Attainment } \\
\hline Some high school or less & 37.2 \\
\hline Grad high school/GED & 32.7 \\
\hline Some College/Voc/Tech & 15.0 \\
\hline Grad college/postgrad & 12.7 \\
\hline Declined/Unavailable & 2.4 \\
\hline \multicolumn{2}{|l|}{ Marital Status } \\
\hline Married & 24.8 \\
\hline Not Married & 75.2 \\
\hline \multicolumn{2}{|l|}{ Smoking Status } \\
\hline Current Smoker & 19.3 \\
\hline Former Smoker & 7.2 \\
\hline Never Smoker & 73.5 \\
\hline Mean BMI $\left(\mathrm{kg} / \mathrm{m}^{2}\right)^{\mathrm{a}}$ & $30.0(9.8)$ \\
\hline Mean $\mathrm{PM}_{2.5}\left(\mu \mathrm{g} / \mathrm{m}^{3}\right)^{\mathrm{b}}$ & $10.0(1.4)$ \\
\hline \multicolumn{2}{|c|}{$\begin{array}{l}\text { *If not available from initial visit, data obtained from the visit most proximate to } \\
\text { initial visit within the 2004-2015 timeframe }\end{array}$} \\
\hline \multicolumn{2}{|c|}{ a \% Missing (n): BMI: 4.8\% (193) } \\
\hline${ }^{\mathrm{b}} \mathrm{PM}_{2.5}$ concentration at initial vi & \\
\hline
\end{tabular}

Table 2 Association of fine particulate matter $\left(\mathrm{PM}_{2.5}\right)$ (in exposure tertiles) and Polycystic Ovarian Morphology $(n=3994)$ (complete analysis)

\begin{tabular}{clll}
\hline & \# Cases & HR $(\mathbf{9 5} \% \mathbf{~ C l})^{\mathbf{a}}$ & HR $(\mathbf{9 5 \%} \mathbf{C l})^{\mathbf{b}}$ \\
\hline PM 2.5 $\left(\mu \mathrm{g} / \mathrm{m}^{3}\right)$ & & & \\
$4.90-9.70$ & 798 & Reference & Reference \\
$9.80-11.30$ & 319 & $1.13(0.88,1.44)$ & $1.12(0.88,1.43)$ \\
$11.40-17.50$ & 70 & $0.88(0.61,1.25)$ & $0.89(0.62,1.28)$
\end{tabular}

${ }^{a}$ Basic model: stratified by age in years and calendar year in the Cox model

${ }^{\mathrm{b}}$ Additionally adjusted for race, education, marital status, smoking status

(95\% CI: 0.14, 5.90), and 0.60 (95\% CI: 0.23, 1.59), respectively (Table 4, Fig. 2). HRs in our sensitivity analysis, restricted to women who never moved, were similar to those for the entire cohort: HRs comparing the second and third tertiles to the reference tertile were 1.25 (95\% CI: $0.68,2.28)$ and 0.84 (95\% CI: $0.33,2.15)$, respectively (Table S1). HRs modeling continuous air pollution were null (Table S2).

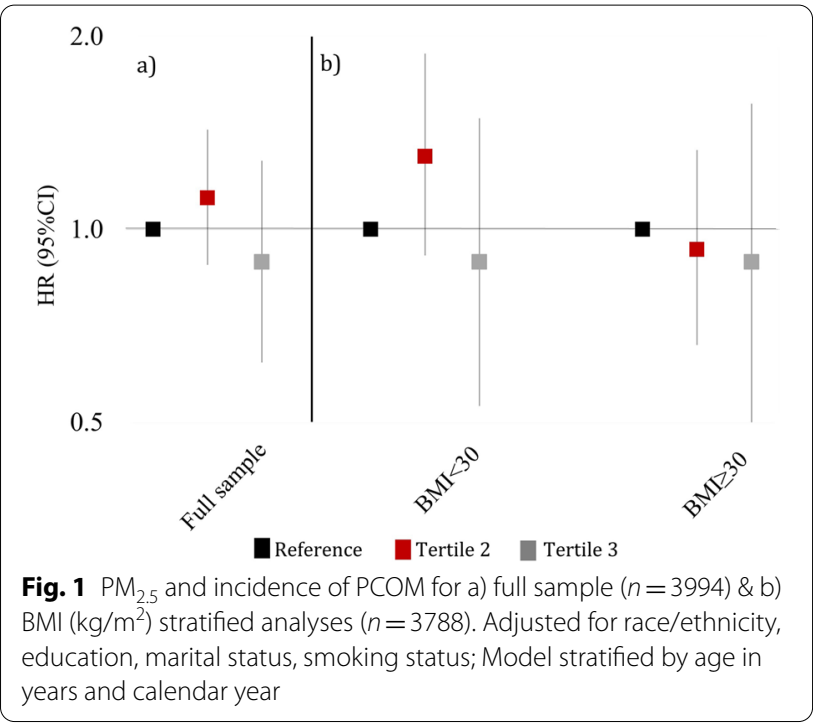

\section{Discussion}

In this population of women who attended clinic visits at $\mathrm{BMC}$, long-term $\mathrm{PM}_{2.5}$ concentrations were not appreciably associated with incidence of PCOM. We observed associations that were inconsistent in direction across tertiles, with no evidence of a dose response relationship. We also found little variation in estimates across race/ ethnicity categories, and slight variations across BMI categories, though estimates were imprecise.

Previous studies evaluating the association between air pollution and women's reproductive health outcomes have been limited. A study of 133 Polish women of reproductive age found that higher concentrations of $\mathrm{PM}_{10}$, as measured by municipal-level monitoring data, were associated with luteal phase shortening; however, the study did not observe any effect on follicular phase or overall cycle length [45]. A time-series analysis from northwestern China recorded more than 51,893 outpatient visits for menstrual disorders and found that higher short-term ambient $\mathrm{PM}_{10}$ concentrations were associated with more outpatient visits for menstrual disorders, with a stronger effect observed among females aged 18-29 years [46]. Furthermore, a cross-sectional study of 34,832 women from the Nurses' Health Study II observed an association between average total suspended particles with increased odds of androgen excess irregularity phenotypes and lengthened time to cycle regularity [22]. However, none of these studies investigated PCOM explicitly, nor did they assess exposure to fine particulate matter.

Although there is no previous research on air pollution and PCOM, one prior study by Lin et al. has evaluated the relationship between fine particulate matter and PCOS. This prospective Taiwanese study observed 
Table 3 Association of fine particulate matter $\left(\mathrm{PM}_{2.5}\right)$ (in exposure tertiles) and Polycystic Ovarian Morphology, by BMl status (<30 vs. $\left.>=30 \mathrm{~kg} / \mathrm{m}^{2}\right)^{\mathrm{a}}(n=3788)$

\begin{tabular}{|c|c|c|c|c|c|}
\hline & & $\begin{array}{l}<30 \mathrm{~kg} / \mathrm{m}^{2} \\
n=2174\end{array}$ & & & $\begin{array}{l}>=30 \mathrm{~kg} / \mathrm{m}^{2} \\
n=1614\end{array}$ \\
\hline & \# Cases & HR $(95 \% \mathrm{Cl})$ & & \# Cases & HR (95\% Cl) \\
\hline \multicolumn{6}{|l|}{ PM $2.5\left(\mu \mathrm{g} / \mathrm{m}^{3}\right)$} \\
\hline $5.10-9.70$ & 441 & Reference & $5.0-9.70$ & 330 & Reference \\
\hline $9.80-11.30$ & 171 & $1.30(0.91,1.88)$ & $9.80-11.30$ & 134 & $0.93(0.66,1.33)$ \\
\hline $11.40-14.80$ & 35 & $0.89(0.53,1.49)$ & $11.40-17.50$ & 26 & $0.89(0.50,1.57)$ \\
\hline
\end{tabular}

a Stratified by age in years and calendar year in the Cox model; Adjusted for race, education, marital status, smoking status

Table 4 Association of tertile fine particulate matter $\left(\mathrm{PM}_{2.5}\right)$ exposure and Polycystic Ovarian Morphology, by race/ethnicity ${ }^{\mathrm{a}}$

\begin{tabular}{lllll}
\hline & $\begin{array}{l}\text { Black/African American } \\
\boldsymbol{n}=\mathbf{2 3 3 6}\end{array}$ & $\begin{array}{l}\text { Hispanic/Latino } \\
\boldsymbol{n = 2 0 4}\end{array}$ & $\begin{array}{l}\text { White } \\
\boldsymbol{n}=\mathbf{6 1 0}\end{array}$ & $\begin{array}{l}\text { Other } \\
\boldsymbol{n}=\mathbf{1 9 0}\end{array}$ \\
\hline PM 2.5 $\left(\boldsymbol{\mu g} / \mathrm{m}^{3}\right)$ & & & & Reference \\
$4.90-9.70$ & Reference & Reference & $0.99(0.51,1.90)$ & $1.12(0.87,1.43)$ \\
$9.80-11.30$ & $0.97(0.72,1.33)$ & $0.80(0.20,3.27)$ & $0.60(0.23,1.59)$ & $0.83(0.58,1.19)$ \\
$11.40-17.50$ & $0.73(0.44,1.20)$ & $0.93(0.14,5.90)$ & &
\end{tabular}

a Stratified by age in years and calendar year; Adjusted for education, marital status, smoking status;

Displaying categories for those that self-identified as Black/African America, Hispanic Latino, and White or as another race/ethnicity

$\sim 16.5 \%$ of participants declined to answer and were not included in this analysis

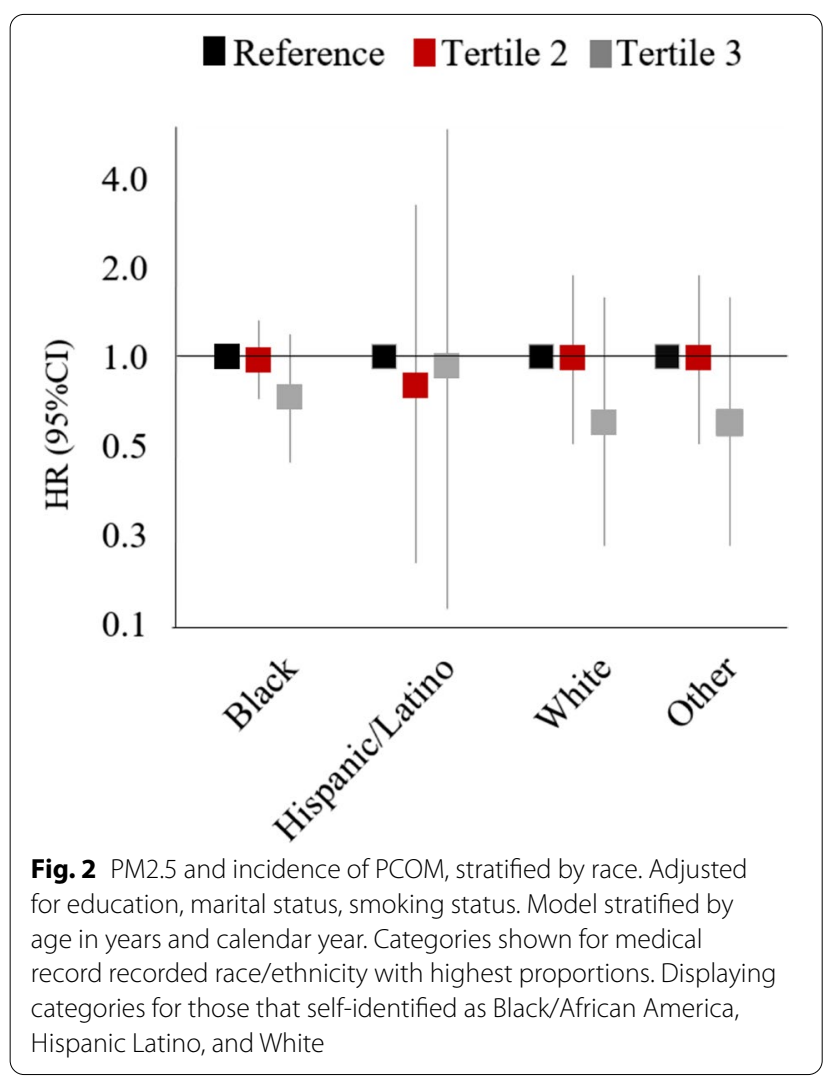

that exposure to $\mathrm{PM}_{2.5}$ at the fourth (34.78-67.45 ppb) vs. first quartile (22.49-27.23 ppb) was associated with a 3.56-fold increased risk of PCOS (95\% CI: 3.05-4.15) [25]. While the investigators examined PCOS diagnosed with ICD-9 CM codes, they were able to evaluate $\mathrm{PM}_{2.5}$ concentrations one year before diagnosis but did not have a longer follow-up, which may have overlooked part of the relevant exposure window within this population. Furthermore, Lin et al. were not able to evaluate effects at lower levels of exposure that are more common in the United States and other countries (mean and $90^{\text {th }}$ percentile weighted annual average across U.S. trend sites in 2019: 7.7, $9.5 \mu \mathrm{g} / \mathrm{m}^{3}$ ) [47] or to assess the potential for a threshold effect, given the relatively high $\mathrm{PM}_{2.5}$ concentrations in the cohort (mean \pm standard deviation daily concentrations of $\mathrm{PM}_{2.5}: 30.9 \pm 6.2 \mu \mathrm{g} / \mathrm{m}^{3}$ ). Our study has been able to fill a gap in the literature by specifically evaluating the association between long-term $\mathrm{PM}_{2.5}$ and PCOM more commonly observed at lower levels of exposure.

Limitations of the current study include possible restricted generalizability. Our study was limited to women receiving care at $\mathrm{BMC}$ and who had an indication for repeated pelvic ultrasounds. Additionally, our EMR dataset was not designed as a traditional 
prospective cohort study since EMR and air pollution data were both collected before the start of our investigation. However, we were able to assess those at risk of PCOM by only including women with normal ovaries at the first ultrasound visit and at least one repeated pelvic ultrasound examination thereafter to determine development of PCOM. Furthermore, we were unable to confirm if women received care and/or ultrasound examinations at another facility during the timeframe of this analysis. We therefore may not have been able to precisely assess the time to PCOM diagnosis for these women, if, for instance, diagnosis occurred prior to their subsequent ultrasound at BMC. The number of ultrasounds that women underwent and the time between each ultrasound was also not uniform across women. Since PCOM may not cause acute symptoms that indicate an immediate ultrasound, and as women were not screened for PCOM at regular intervals for detection, women may have contributed person time after PCOM occurred but before PCOM was detected via ultrasound. We additionally did not have information accessible to link $\mathrm{PM}_{2.5}$ to address changes over time. Consequently, the participant's address at the initial visit was used to assess $\mathrm{PM}_{2.5}$ concentration. Nevertheless, our findings were comparable to results for the entire analytic sample when we restricted our sample to those that had not moved addresses throughout the study. Furthermore, we could not expand our study further to other pollutants in addition to $\mathrm{PM}_{25}$ because geocoded data on these other components were not available at the time of our analysis.

For this hospital sourced radiological data, ultrasound assessment was not timed to menstrual cycle day, which was also a limitation in our study as we were not able to account for influence of cycle day on ultrasound imaging $[48,49]$. However, this study does not evaluate antral follicle count (AFC) measurements on the basal phase of the menstrual cycle (cycle day 2-4), as it was not designed to evaluate AFC in relation to PCOM $[50,51]$. Given the age of the population (mean: 31.1; standard deviation: 7.6), we suspect within person variation to be limited. Additionally, those with PCOM at baseline were excluded to evaluate PCOM incidence. Furthermore, our algorithm for detection of PCOM used text from the radiologic report as a proxy, rather than directly counting follicles from ultrasound images. Methods for determining the presence of PCOM in ultrasound reports demonstrated high sensitivity and specificity, and accuracy of up to $97.6 \%$ (95\% CI: $96.5,98.5 \%$ ) when comparing machine learning text algorithm used for classification of PCOM in pelvic ultrasounds based on the radiographic report compared to the hand-labeled test set [28]. However, misclassification of the outcome may have occurred if some providers did not report the necessary information to characterize $\mathrm{PCOM}$, or if there were discrepancies in ultrasound reading by the technician. We also observed marginal inverse associations among women with obesity (BMI $\left.\geq 30 \mathrm{vs} .<30 \mathrm{~kg} / \mathrm{m}^{2}\right)$ for both higher level tertiles compared to the reference tertile. Yet, results suggesting a potential reduction in incidence of PCOM among obese women may be due to detection bias, as pelvic examinations may be less sensitive for detecting PCOM among obese women.

Additionally, we defined our detection of PCOM based on Rotterdam criteria. Recently, alternative criteria have been proposed including a higher follicle threshold $(\geq 25$ follicles per ovary), but the sensitivity of these criteria is still being considered [50,52]. To add further complexity, women with regular menstrual cycles can be defined as having PCOM in the setting of very robust ovarian reserve or younger age [53]. A previous study found the prevalence of polycystic ovaries assessed by antral follicle count to be $32 \%$ and that prevalence decreased with age [53]. Future studies should focus on the dynamic aspects of ovarian physiology in an unselected population and include measures of ovarian volume, follicle counts in the basal phase of the menstrual cycle corresponding to follicular recruitment, and include cycle length in the analysis, rather than focusing of PCOM alone.

Although the EMR dataset did not permit us to conduct a traditional prospective cohort study, a strength of our analysis was that we were able to assess those at risk of PCOM over time by having access to baseline and follow-up data. We included women with normal ovaries at the first ultrasound visit and at least one repeated pelvic ultrasound examination thereafter to determine incidence of PCOM. Furthermore, to our knowledge, this is the first study to evaluate exposure to fine particulate matter in relation PCOM. Additional strengths include the efficiency of this analysis in integrating retrospective air pollution assessment in evaluation of reproductive disease pathophysiology. Furthermore, the rich set of EMR data provided a large sample size of nearly 4,000 women and the ability to control for important confounding variables.

\section{Conclusions}

Among a population of reproductive-age women receiving clinical care within our cohort, $\mathrm{PM}_{2.5}$ concentrations were generally not associated with higher risk of PCOM at the fine particulate matter levels within our cohort. No dose response relationships were observed nor were estimates appreciably different across race/ethnicity. Future studies with greater variation in exposure levels and additional data on ovarian physiology in unselected populations would further extend these findings. 


\section{Supplementary Information}

The online version contains supplementary material available at https://doi. org/10.1186/s12940-022-00835-1.

Additional file 1:Table S1. Association of tertile fine particulate matter (PM2.5) and Polycystic Ovarian Morphology ( $n=682)$ among those participants that never moved. Table S2. Association of quartile fine particulate matter (PM2.5) exposure and Polycystic Ovarian Morphology (complete analysis, continuous). Figure S1. PM2.5 Cumulative Average by Year, averaged across participants (2003-2016). Figure S2. Directed Acyclic Graph used to identify covariates for inclusion in regression models as confounding variables; Note: Figure generated using DAGitty v2.3 (Textor and Hardt 2011). Abbreviations: SES, socioeconomic status; PM2.5, fine particulate matter.

\section{Acknowledgements}

We would like to acknowledge Linda Rosen at the Clinical Data Warehouse for support in assembling the clinical dataset and Pratik Shingru for his contributions to processing Census data, and the Washington University in Saint Louis Atmospheric Composition Analysis Group (https://sites.wustledu/acag/) for making their air pollution models available to researchers.

\section{Authors' contributions}

VF-analysis, interpretation, and manuscript writing. JC — code development and output to obtain PCOM data from patient medical records, major contributor in editing the manuscript. KL - provided fine particulate matter and address data, interpretation, major contributor in editing the manuscript. AA-methodology, interpretation, major contributor in editing the manuscript. SM concept, interpretation, major contributor in writing the manuscript. All authors read and approved the final manuscript.

\section{Funding}

Funding for this project was provided in part by the Boston University School of Public health Career Catalyst pilot award funded by the Idea Hub and Robert F. Meenan Faculty Support Fund. Funding was also provided through a NLM training grant to the Computation and Informatics in Biology and Medicine Training Program (NLM 5T15LM007359).

\section{Availability of data and materials}

The datasets generated and/or analyzed during the current study are not publicly available due to confidentiality agreements and the privacy of individuals within the electronic medical records data.

\section{Declarations}

Ethics approval and consent to participate

The BUMC and BUSM Institutional Review Board approved the protocol.

\section{Consent for publication}

Not Applicable.

\section{Competing Interests}

The authors have no conflicts of interest to declare.

\section{Author details}

${ }^{1}$ Department of Environmental Health, Harvard T.H. Chan School of Public Health, Boston, MA, USA. ${ }^{2}$ Department of Biostatistics and Medical Informatics, University of Wisconsin, 702 West Johnson Street, Madison, WI, USA. ${ }^{3}$ Department of Epidemiology, Boston University School of Public Health, Boston, MA, USA. ${ }^{4}$ Obstetrics and Gynecology, Massachusetts General Hospital, 55 Fruit Street, Boston, MA 02114-2696, USA. ${ }^{5}$ Department of Environmental Health, Boston University School of Public Health, Boston, MA, USA.

Received: 30 July 2021 Accepted: 19 January 2022

Published online: 18 February 2022

\section{References}

1. Laven JSE, Imani B, Eijkemans MJC, Fauser BCJM. New approach to polycystic ovary syndrome and other forms of anovulatory infertility. Obstet Gynecol Surv. 2002;57(11):755-67.

2. Rotterdam ESHRE/ASRM-Sponsored PCOS Consensus Workshop Group. Revised 2003 consensus on diagnostic criteria and long-term health risks related to polycystic ovary syndrome. Fertil Steril. 2004;81(1):19-25.

3. Mikhael S, Punjala-Patel A, Gavrilova-Jordan L. Hypothalamic-PituitaryOvarian Axis Disorders Impacting Female Fertility. Biomedicines. 2019;7(1):5.

4. Pigny P, Merlen E, Robert Y, Cortet-Rudelli C, Decanter C, Jonard S, et al. Elevated serum level of anti-mullerian hormone in patients with polycystic ovary syndrome: relationship to the ovarian follicle excess and to the follicular arrest. J Clin Endocrinol Metab. 2003;88(12):5957-62.

5. Futterweit W, Yeh HC, Mechanick Jl. Ultrasonographic study of ovaries of 19 women with weight loss-related hypothalamic oligo-amenorrhea. Biomed Pharmacother Biomedecine Pharmacother. 1988;42(4):279-83.

6. Schachter M, Balen AH, Patel A, Jacobs HS. Hypogonadotropic patients with ultrasonographically detected polycystic ovaries: endocrine response to pulsatile gonadotropin-releasing hormone. Gynecol Endocrinol. 1996;10(5):327-35.

7. Sum M, Warren MP. Hypothalamic amenorrhea in young women with underlying polycystic ovary syndrome. Fertil Steril. 2009;92(6):2106-8.

8. Kaltsas GA, Korbonits M, Isidori AM, Webb JA, Trainer PJ, Monson JP, et al. How common are polycystic ovaries and the polycystic ovarian syndrome in women with Cushing's syndrome? Clin Endocrinol (Oxf). 2000;53(4):493-500

9. Inan C, Karadag C. Correlation between ovarian morphology and biochemical and hormonal parameters in polycystic ovary syndrome. Pak Med Sci. 2016;32(3):742-5.

10. Villarroel C, Merino PM, López P, Eyzaguirre FC, Van Velzen A, Iñiguez G, et al. Polycystic ovarian morphology in adolescents with regular menstrual cycles is associated with elevated anti-Mullerian hormone. Hum Reprod Oxf Engl. 2011;26(10):2861-8.

11. Jeong JY, Kim MK, Lee I, Yun J, Won YB, Yun BH, et al. Polycystic ovarian morphology is associated with primary dysmenorrhea in young Korean women. Obstet Gynecol Sci. 2019;62(5):329-34.

12. Goldman M, Troisi R, Rexrode K. 2012. Women and Health [Internet]. 2nd Edition. Academic Press. Cited 2021 Feb 16. Available from: https://www. elsevier.com/books/women-and-health/goldman/978-0-12-384978-6

13. Rudel RA, Perovich LJ. Endocrine disrupting chemicals in indoor and outdoor air. Atmospheric Environ Oxf Engl 1994. 2009;43(1):170-81.

14. Boulet SL, Zhou Y, Shriber J, Kissin DM, Strosnider H, Shin M. Ambient air pollution and in vitro fertilization treatment outcomes. Hum Reprod Oxf Engl. 2019;02;34(10):2036-43.

15. Carré J, Gatimel N, Moreau J, Parinaud J, Leandri R. Influence of air quality on the results of in vitro fertilization attempts: A retrospective study. Eur J Obstet Gynecol Reprod Biol. 2017;210:116-22.

16. Nobles CJ, Schisterman EF, Ha S, Buck Louis GM, Sherman S, Mendola P. Time-varying cycle average and daily variation in ambient air pollution and fecundability. Hum Reprod Oxf Engl. 2018;01;33(1):166-76.

17. Mahalingaiah S, Hart JE, Laden F, Farland LV, Hewlett MM, Chavarro J, et al. Adult air pollution exposure and risk of infertility in the Nurses' Health Study II. Hum Reprod Oxf Engl. 2016;31(3):638-47.

18. La Marca A, Spaggiari G, Domenici D, Grassi R, Casonati A, Baraldi E, et al. 2020. Elevated levels of nitrous dioxide are associated with lower AMH levels: a real-world analysis. Hum Reprod [Internet]. Cited 2020 Oct 30. Available from: https://academic.oup.com/humrep/advance-article/ doi/https://doi.org/10.1093/humrep/deaa214/5909140

19. Tomei G, Ciarrocca M, Fortunato BR, Capozzella A, Rosati MV, Cerratti D, et al. Exposure to traffic pollutants and effects on 17-beta-estradiol (E2) in female workers. Int Arch Occup Environ Health. 2006;80(1):70-7.

20. Giorgis-Allemand L, Thalabard JC, Rosetta L, Siroux V, Bouyer J, Slama R. Can atmospheric pollutants influence menstrual cycle function? Environ Pollut Barking Essex. 2020;257:113605.

21. Liang Z, Xu C, Fan Y, Liang Z-Q, Kan H-D, Chen R-J, et al. Association between air pollution and menstrual disorder outpatient visits: A timeseries analysis. Ecotoxicol Environ Saf. 2020;192:110283.

22. Mahalingaiah S, Missmer SE, Cheng JJ, Chavarro J, Laden F, Hart JE. Perimenarchal air pollution exposure and menstrual disorders. Hum Reprod Oxf Engl. 2018;01;33(3):512-9. 
23. Ogliari KS, Lichtenfels AJ de FC, de Marchi MRR, Ferreira AT, Dolhnikoff M, Saldiva PHN. Intrauterine exposure to diesel exhaust diminishes adult ovarian reserve. Fertil Steril. 2013;99(6):1681-8.

24. Gai H-F, An J-X, Qian X-Y, Wei Y-J, Williams JP, Gao G-L. Ovarian Damages Produced by Aerosolized Fine Particulate Matter (PM2.5) Pollution in Mice: Possible Protective Medications and Mechanisms. Chin Med J (Engl). 2017;130(12):1400-10.

25. Lin S-Y, Yang Y-C, Chang CY-Y, Lin C-C, Hsu W-H, Ju S-W, et al. 2019. Risk of Polycystic Ovary Syndrome in Women Exposed to Fine Air Pollutants and Acidic Gases: A Nationwide Cohort Analysis. Int J Environ Res Public Health [Internet]. Cited 2020 Oct 30. 16(23). Available from: https://www. ncbi.nlm.nih.gov/pmc/articles/PMC6926786/

26. Boston Medical Center. 2021. About Us | Boston Medical Center [Internet]. Cited 2021 May 20. Available from: https://www.bmc.org/about-us

27. Boston Medical Center. Boston Medical Center Race and Ethnicity Profiles. Boston Medical Center; 2009. http://www.bumc.bu.edu/crro/files/2010/ 06/Boston-Medical-Center-_Patient-Profile-Table-2.pdf. Cited: 2020 Aug 31.

28. Cheng JJ, Mahalingaiah S. 2019. Data mining polycystic ovary morphology in electronic medical record ultrasound reports. Fertil Res Pract [Internet]. Cited 2020 Aug 31. 5. Available from: https://www.ncbi.nlm. nih.gov/pmc/articles/PMC6886196/

29. Hammer MS, van Donkelaar A, Li C, Lyapustin A, Sayer AM, Hsu NC, et al. Global Estimates and Long-Term Trends of Fine Particulate Matter Concentrations (1998-2018). Environ Sci Technol. 2020:54(13):7879-90.

30. Di Q, Kloog I, Koutrakis P, Lyapustin A, Wang Y, Schwartz J. Assessing PM2.5 Exposures with High Spatiotemporal Resolution across the Continental United States. Environ Sci Technol. 2016;50(9):4712-21.

31. Donkelaar A van, Martin RV, Park RJ. Estimating ground-level PM2.5 using aerosol optical depth determined from satellite remote sensing. J Geophys Res Atmospheres [Internet]. 2006 [cited 2020 Aug 21];111(D21). Available from: https://agupubs.onlinelibrary.wiley.com/doi/abs/https:// doi.org/10.1029/2005JD006996

32 Kloog I, Koutrakis P, Coull BA, Lee HJ, Schwartz J. Assessing temporally and spatially resolved PM 2.5 exposures for epidemiological studies using satellite aerosol optical depth measurements. Atmos Environ. 2011;45:6267-75.

33. van Donkelaar A, Martin RV, Brauer M, Hsu NC, Kahn RA, Levy RC, et al. Global Estimates of Fine Particulate Matter using a Combined Geophysical-Statistical Method with Information from Satellites, Models, and Monitors. Environ Sci Technol. 2016;50(7):3762-72.

34. van Donkelaar Aaron, Martin Randall V, Brauer M, Boys Brian L. Use of Satellite Observations for Long-Term Exposure Assessment of Global Concentrations of Fine Particulate Matter. Environ Health Perspect. 2015;123(2):135-43.

35. Balen A. Ovulation induction for polycystic ovary syndrome. Hum Fertil. 2000;3(2):106-11.

36. Jonard S, Robert Y, Cortet-Rudelli C, Pigny P, Decanter C, Dewailly D. Ultrasound examination of polycystic ovaries: is it worth counting the follicles? Hum Reprod. 2003;18(3):598-603.

37. Pache TD, Wladimiroff JW, Hop WC, Fauser BC. How to discriminate between normal and polycystic ovaries: transvaginal US study. Radiology. 1992;183(2):421-3.

38. National Institute of Health. 2013. Body Mass Index Table 1 [Internet]. [cited 2021 Jan 25]. Available from: https://www.nhlbi.nih.gov/health/ educational/lose_wt/BMl/bmi_tbl.htm

39. Hernán MA, Hernández-Díaz S, Werler MM, Mitchell AA. Causal knowledge as a prerequisite for confounding evaluation: an application to birth defects epidemiology. Am J Epidemiol. 2002;155(2):176-84.

40. Merkin SS, Azziz R, Seeman T, Calderon-Margalit R, Daviglus M, Kiefe C, et al. Socioeconomic Status and Polycystic Ovary Syndrome. J Womens Health. 2011;20(3):413-9.

41. Hajat A, Hsia C, O'Neill MS. Socioeconomic Disparities and Air Pollution Exposure: A Global Review. Curr Environ Health Rep. 2015;2(4):440-50.

42. Pau CT, Keefe CC, Welt CK. Cigarette smoking, nicotine levels and increased risk for metabolic syndrome in women with polycystic ovary syndrome. Gynecol Endocrinol Off J Int Soc Gynecol Endocrinol. 2013;29(6):551-5

43. Sowers MF, Beebe JL, McConnell D, Randolph J, Jannausch M. Testosterone concentrations in women aged $25-50$ years: associations with lifestyle, body composition, and ovarian status. Am J Epidemiol. 2001;153(3):256-64.

44. National Research Council (US) Committee on Passive Smoking. 1986 Environmental Tobacco Smoke: Measuring Exposures and Assessing Health Effects [Internet]. Washington (DC): National Academies Press (US). Cited 2021 Jul 15. Available from: http://www.ncbi.nlm.nih.gov/books/ NBK219205/

45. Merklinger-Gruchala A, Jasienska G, Kapiszewska M. Effect of Air Pollution on Menstrual Cycle Length-A Prognostic Factor of Women's Reproductive Health. Int J Environ Res Public Health. 2017;14(7):816. https://doi.org/10. 3390/ijerph14070816. PMID: 28726748; PMCID: PMC5551254.

46. Liang Z, Xu C, Fan Y-N, Liang Z-Q, Kan H-D, Chen R-J, et al. Association between air pollution and menstrual disorder outpatient visits: A timeseries analysis. Ecotoxicol Environ Saf. 2020;192:110283.

47. US EPA O. 2020. Particulate Matter (PM2.5) Trends [Internet]. US EPA. Cited 2020 Dec 21. Available from: https://www.epa.gov/air-trends/parti culate-matter-pm25-trends

48. Chun S. Inter-ovarian differences in ultrasound markers of ovarian size in women with polycystic ovary syndrome. Clin Exp Reprod Med. 2019;46(4):197-201.

49. Jokubkiene L, Sladkevicius P, Rovas L, Valentin L. Assessment of changes in volume and vascularity of the ovaries during the normal menstrual cycle using three-dimensional power Doppler ultrasound. Hum Reprod. 2006;21(10):2661-8.

50. Dewailly D, Lujan ME, Carmina E, Cedars MI, Laven J, Norman RJ, et al. Definition and significance of polycystic ovarian morphology: a task force report from the Androgen Excess and Polycystic Ovary Syndrome Society. Hum Reprod Update. 2014;20(3):334-52.

51. van Disseldorp J, Lambalk CB, Kwee J, Looman CWN, Eijkemans MJC, Fauser BC, et al. Comparison of inter- and intra-cycle variability of anti-Mullerian hormone and antral follicle counts. Hum Reprod. 2010;25(1):221-7

52. Quinn MM, Kao C-N, Ahmad A, Lenhart N, Shinkai K, Cedars MI, et al. Raising threshold for diagnosis of polycystic ovary syndrome excludes population of patients with metabolic risk. Fertil Steril. 2016;106(5):1244-51.

53. Johnstone EB, Rosen MP, Neril R, Trevithick D, Sternfeld B, Murphy R, et al. The polycystic ovary post-rotterdam: a common, age-dependent finding in ovulatory women without metabolic significance. J Clin Endocrinol Metab. 2010;95(11):4965-72.

\section{Publisher's Note}

Springer Nature remains neutral with regard to jurisdictional claims in published maps and institutional affiliations.

Ready to submit your research? Choose BMC and benefit from

- fast, convenient online submission

- thorough peer review by experienced researchers in your field

- rapid publication on acceptance

- support for research data, including large and complex data types

- gold Open Access which fosters wider collaboration and increased citations

- maximum visibility for your research: over $100 \mathrm{M}$ website views per year

At BMC, research is always in progress.

Learn more biomedcentral.com/submissions 